\title{
FACTORS OF NAMING EFFICIENCY
}

\author{
Olga V. Gosteva \\ Voronezh State Technical University, Voronezh, Russian Federation
}

\begin{abstract}
The article covers several factors of efficient commercial naming process. The linguistic study of proper names of businesses in Voronezh that we have conducted shows that such naming units are indirect speech acts with the intention of causing action. Their influence on an addressee is implicit. Such business names attain addressee persuasion by answering one of the following questions: "Who sells? What is sold? Whom is it sold?" The questions denote the three components of the commercial naming model that we have formulated. Any business name can be related to one of the components of the model. Efficiency of a business name depends on how clearly the author presents the selected component. Addressee factor is also important since the evaluation of a business name depends on the difficulty of its interpretation, character of associations (negative or positive) and the possibility of association with other business names. The article provides information about the proportions of the two types of business names, that is business names that reflect features of one particular business sphere and those that can be related to different spheres, depending on the type of business. The article also characterizes the possibility of using the same linguistic unit for naming businesses belonging to different types.

Key words: naming, proper name, business, commercial naming, addressee factor, indirect speech act, commercial naming model.

Citation. Gosteva O.V. Factors of Naming Efficiency.Vestnik Volgogradskogo gosudarstvennogo universiteta. Serija 2, Jazykoznanije [Science Journal of Volgograd State University. Linguistics], 2017, vol. 16, no. 2, pp. 175-180. (in Russian). DOI: https://doi.org/10.15688/jvolsu2.2017.2.19.
\end{abstract}

УДК $811^{\prime} 42: 338$

ББК 81.055 .513
Дата поступления статьи: 20.02.2017

Дата принятия статьи: 17.04.2017

\section{ФАКТОРЫ ЭФФЕКТИВНОСТИ НЕЙМИНГА}

\section{Ольга Владимировна Гостева}

Воронежский государственный технический университет, г. Воронеж, Российская Федерация

Аннотация. В статье охарактеризованы факторы обеспечения эффективности процесса коммерческого именования. В результате лингвистического анализа имен собственных бизнес-объектов (ИСБО) г. Воронежа выявлено, что ИСБО, будучи косвенными речевыми актами с интенцией побуждения к действию, оказывают влияние на адресата имплицитно. Оно реализуется посредством актуализации одного из компонентов предложенной нами модели коммерческой номинации «кто-что-кому продает». Обнаружено, что любое наименование бизнес-объекта может быть соотнесено с одним из компонентов модели. Установлено, что эффективность номинации бизнес-объектов обусловлена четкостью речевого представления выбранного для фиксации в названии компонента номинации, а также учетом фактора адресата: показано, что на оценку наименования адресатом влияет затрудненность толкования ИСБО, характер ассоциаций (негативные или позитивные), возможность ассоциации с названиями других бизнес-объектов. خे. Описано соотношение двух видов ИСБО (названий, указывающих на определенную сферу бизнеса, и ИСБО, имеющих широкие возможности применения) и их зависимость от типа бизнес-объектов, а также о охарактеризованы возможности применения одной и той же языковой единицы для индивидуализации

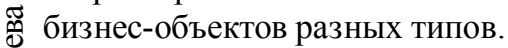

Изложенный в статье материал может быть использован специалистами-неймерами при разработке наименований бизнес-объектов. 
Ключевые слова: нейминг, имя собственное, бизнес-объект, коммерческая номинация, фактор адресата, косвенный речевой акт, модель коммерческой номинации.

Цитирование. Гостева О. В. Факторы эффективности нейминга // Вестник Волгоградского государственного университета. Серия 2, Языкознание. - 2017. - Т. 16, № 2. - C. 175-180. - DOI: https://doi.org/ 10.15688/jvolsu2.2017.2.19.

1

Развитие стиля рекламы требует появления неймеров - специалистов с хорошим уровнем филологической подготовки, чьей задачей является создание номинации товара или бизнес-объекта (магазина, фирмы), способствующей формированию привлекательного для потенциального потребителя образа денотата. Грамотно разработанное название оказывает на адресата нужное продавцу воздействие и подводит к совершению покупки соответствующих товаров или услуг.

Закономерно возникает вопрос о том, какие аспекты номинативного и коммуникативного характера необходимо учитывать для того, чтобы создать эффективное коммерческое наименование. В учебной литературе по маркетингу (см., например: [Пименов]) можно встретить описание этапов подготовки к созданию номинации, рекомендации относительно того, каким должно и не должно быть коммерческое название, а также примерный набор приемов именования и возможных ошибок. Так, отмечается, что номинация должна быть легко читаемой, понятной, указывается, что название не должно быть неблагозвучным или вызывающим отрицательные ассоциации. Предлагаемые приемы номинации варьируются от использования фамилий и имен мифологических героев до аббревиатур и заимствований.

Вся информация представлена в виде рекомендаций. При этом вне поля зрения специалистов-маркетологов остается собственно работа с языковыми средствами номинации, сущность и механизмы данного процесса, закономерности, действующие в сфере коммерческого именования (нейминга).

2

Проводимое нами с 2010 г. исследование (некоторые его результаты отражены в [Стиль рекламы..., 2016; Что в имени?, 2016]) одной из разновидностей коммерческой номинации - имен собственных бизнес-объектов (далее - ИСБО) - позволяет сформулировать факторы, определяющие эффективность нейминга. Рассмотрим данные факторы. В качестве примеров в статье приводятся наименования бизнес-объектов г. Воронежа (авторская картотека составляет 387 названий).

Необходимым условием создания эффективного ИСБО выступает ориентация на адресата. И.А. Стернин пишет: «...одним из важнейших факторов речевого воздействия является так называемый фактор адресата - то есть эффективный учет особенностей той аудитории, на которую направлено речевое воздействие» [Стернин, 2004, с. 172]. В связи с этим разработке номинации бизнес-объекта предшествует изучение ее целевой аудитории: определение возраста, пола, социального статуса, образования, мотиваций, потребностей, желаний адресатов и т. д. Перечисленные параметры обусловливают понимание ИСБО.

2.1. Для успешной коммуникации, осуществляемой посредством речевого акта, которым является ИСБО, важна языковая и культурно-историческая общность адресанта и адресата. Подобная общность позволяет адресанту прогнозировать восприятие ИСБО адресатом. Иногда (видимо, рассчитывая на благозвучность языковой единицы) адресант создает номинации, семантика которых для адресата затемнена. В качестве примера приведем функционирующие в г. Воронеже названия цветочных магазинов «Аваланж» и «Et cetera». То, что аваланж - название сорта ро3, a et cetera в переводе с латинского означает «и так далее», может быть адресату неизвестно. Затрудненность интерпретации ИСБО влияет на его оценку и снижает эффективность воздействия.

Заметим, что даже при соблюдении параметров, определяющих понимание ИСБО, положительная оценка номинации всей целевой аудиторией практически недостижима, поскольку восприятие всегда индивиду- 
ально. По нашим данным, самые узнаваемые ИСБО получают положительную оценку не более чем у 78 \% адресатов [Лапинская, Гостева, 2015].

2.2. Эффективный нейминг предполагает учет ассоциативных возможностей номинации. Ассоциативность является основой формирования образа бизнес-объекта, и, хотя предвидеть все индивидуальные ассоциации адресата невозможно, следует избегать явно негативных ассоциаций. В качестве примера несоблюдения этого требования приведем название одного из предприятий питания г. Воронежа, специализирующегося на приготовлении блюд японской кухни, - «Сушин Сын». Название вызывает ассоциации с фразеологическим выражением сукин сын. Оно, помеченное в словарях (см., например: [Ожегов, Шведова, 1994]) как просторечное бранное, обозначает негодяя. Опираясь на свой языковой опыт, адресат номинации «Сушин Cынн» может предположить, что как негодяя характеризуют его самого или персонал бизнесобъекта. В обоих случаях привлекательность ИСБО снижается.

При наименовании бизнес-объекта важно с осторожностью использовать языковые единицы, имеющие отрицательные коннотации. Так, название парикмахерской в г. Воронеже «Гламур» может быть отрицательно воспринято некоторыми адресатами, поскольку оно указывает на что-то слишком яркое, бросающееся в глаза и в чем-то противоположное понятию хорошего вкуса. Гламур обозначает показную роскошь, нарочитый шик (Проверка слова). Это слово может вызвать отрицательные ассоциации с человеком, который хочет противопоставить себя окружающим, показать свое превосходство.

Нежелательно создавать номинации, вызывающие ассоциации с другими бизнесобъектами. В качестве примера приведем названия парикмахерских в г. Воронеже «Жар-Птицау» и «Этуаль». Наименование «Жар-Птища» ассоциируется с названием сети ресторанов быстрого обслуживания "Жар Пициа», а название «Этуаль» - с названием сети парфюмерно-косметических магазинов «Л’Этуаль». Подобная ассоциативность, как правило, препятствует положительному восприятию номинации и самого бизнес-объекта. Следовательно, неймер должен знать «язык города», то есть ономастическое пространство того населенного пункта, где предстоит функционировать ИСБО. По этой же причине неймер должен ориентироваться и в разнообразных брендах.

2.3. Неймер должен обладать знаниями в области лексической семантики и учитывать значения, которые актуализируются в случаях именования бизнес-объекта определенного типа. Чтобы проиллюстрировать зависимость восприятия языковой единицы от типа именуемого с ее помощью бизнесобъекта, приведем следующие названия предприятий питания г. Воронежа: название кафе-кондитерской «Прокофий» и наименование сети пиццерий «Время Есть». Использование антропонима Прокофий в качестве номинации кафе актуализирует ассоциации с предложно-падежной конструкцией с предлогом про («про кофий»). Сочетание время eсть в качестве названия пиццерии в первую очередь может быть воспринято не как констатация наличия времени, а как призыв к действию (приему пищи).

2.4. Следует обратить внимание на возможности применения одной и той же языковой единицы для индивидуализации бизнесобъектов разных типов. Существуют ИСБО, называющие реалии, которые связаны с определенной сферой бизнеса, и, если адресат не знает, бизнес-объект какого типа подобное ИСБО именует, он может об этом догадаться. Например, номинация «Кофеварка» (название предприятия питания в г. Воронеже) отражает специфику одной сферы бизнеса. В Воронеже доля названий, указывающих на реалии определенной сферы бизнеса, варьируется в зависимости от типа бизнесобъекта. Так, среди номинаций цветочных магазинов подобные ИСБО составляют $83 \%$ (59 из 71 ИСБО), среди названий парикмахерских $-8 \%$ (8 из 100 номинаций), предприятий питания - $23 \%$ (50 из 216 названий). Однако нами зафиксированы и полифункциональные ИСБО: например, в Воронеже посредством номинации «Престиж» названы автошкола, магазин верхней одежды, парикмахерская и салон красоты.

2.5. Большинство названий бизнес-объектов представляет собой косвенные речевые 


\section{МАТЕРИАЛЫ И СООБЩЕНИЯ}

акты (с интенцией побуждения к действию). Следовательно, ИСБО оказывают опосредованное воздействие на адресата. Кроме того, «информация, содержащаяся в номинациях на вывесках, с одной стороны, исключает категоричность приказа, неуместного при реализации товарно-денежных отношений, с другой стороны, она подводит потенциального покупателя к осознанию независимости от внешнего (речевого) воздействия продавца принятого им, покупателем, решения приобрести рекламируемый товар» [Лапинская, Гостева, 2015, с. 42]. Несмотря на то, что ИСБО имеют четкую прагматическую цель, номинации, которые эксплицитно призывают покупателя к совершению покупки, единичны (например, название сети магазинов «Покупайка»).

ИСБО воспринимаются адресатами, прежде всего как репрезентативы, то есть информативные речевые акты (например, «Мир пальто»), что и обеспечивает эффективность воздействия, тогда как осознание адресатом того, что его принуждают к выполнению определенных действий (совершению покупки), не способствует успешному выполнению ИСБО своих функций. Видя номинацию на вывеске, адресат получает информацию, например о том, кто владеет бизнес-объектом («Татьяна Сулимина»), какова специализация бизнесобъекта («Вермишель») и где он находится («17й Квартал»), какой результат посещения бизнес-объекта обещает адресант ( $К$ Kрасот$\kappa a »)$. В действительности имеет место имплицитное воздействие на адресата, осуществляемое посредством его информирования об удобстве расположения бизнес-объекта, ассортименте товаров, профессионализме персонала, авторитетности продавца и других значимых для адресата характеристиках.

\section{3}

Ассоциативность наименования, выбор компонентов мотивирующей номинации и другие свойства соотносятся с предложенной нами в предыдущих публикациях моделью коммерческой номинации «кто-чтокому продает», компоненты которой указывают на продавца, товар или покупателя [Гостева, 2013]. Любое ИСБО может быть рассмотрено как соответствующее одному из компонентов модели, а приемы именования могут быть подведены под три основные категории. Неймеру следует определить, какой компонент модели «кто-что-кому продает» будет актуализирован в ИСБО, и выбрать прием именования из тех, что соответствуют данному компоненту.

Каждый компонент модели имеет ряд вариантов выражения. Например, компонент «кто продает» реализуется в названиях, включающих антропонимы (личные имена, фамилии владельцев бизнес-объекта и / или их родственников) (подробно такие названия описаны в: [Лапинская, 2016]). В качестве примера приведем название магазина женской верхней одежды в г. Воронеже «Надежда Дорохова». Кроме того, компонент модели коммерческой номинации может быть обозначен опосредованно: он реализуется в названиях, указывающих на адрес бизнес-объекта. Так, ресторан «Кировский» в г. Воронеже назван по расположению на улице Кирова. Этому же компоненту соответствуют номинации, описывающие цветовое оформление бизнес-объекта или его вывески (например, названия парикмахерских г. Воронежа «Домино», «Red»).

Компонент «что продают» реализуется посредством различных вариантов указания на продукцию или услуги бизнес-объекта. Например, номинация может выражать общее обозначение продукции (цветочный магазин «Букет»), указывать на один из представленных товаров (цветочный магазин «Орхидея»), акцентировать идею широты предлагаемого ассортимента (цветочный магазин «Океан цветов»).

Компонент «кому продают» также актуализируется в нескольких вариантах. Например, в номинации может быть указан потенциальный клиент до посещения бизнес-объекта (парикмахерская «Для Всех») и после (парикмахерская «Чародейка»), обозначен обещаемый адресантом результат (парикмахерская «Идеал»).

Осуществление эффективного нейминга предполагает учет ряда факторов. При разработке названия необходимо ориентироваться на целевую аудиторию номинации (фактор адресата). Неймеру следует учитывать ассоциативные возможности языковой единицы, а также 
тип именуемого бизнес-объекта. ИСБО, оказывая воздействующий эффект опосредованно, является косвенным речевым актом. Воздействие достигается с помощью актуализации одного из компонентов модели коммерческой номинации «кто-что-кому продает».

Изложенный в статье материал может быть использован специалистами-неймерами при разработке наименований бизнес-объектов.

\section{СПИСОК ЛИТЕРАТУРЫ}

Гостева, О. В. Семантическая модель коммерческой номинации (на материале названий цветочных магазинов г. Воронежа и г. Бирмингема) / О. В. Гостева // Актуальные проблемы и современные технологии преподавания иностранных языков в неспециальных вузах : материалы 6-й Всерос. с междунар. участием научн.-практ. конф. неязыковых вузов на базе ВГИФК. Воронеж : Научная книга, 2013. - С. 97-99.

Лапинская, И. П. Антропонимы как названия бизнес-объектов / И. П. Лапинская // Русская речь. 2016. - № 1. - С. 76-81.

Лапинская, И. П. Системность имен собственных бизнес-объектов в языке рекламы / И. П. Лапинская, О. В. Гостева // Вестник Воронежского государственного университета. Серия «Лингвистика и межкультурная коммуникация». - 2015. - № 4. - С. 42-47.

Пименов, П. А. Нейминг: как правильно назвать товар или бизнес / П. А. Пименов // Элитариум: центр дистанционного образования. - Электрон. текстовые дан. - Режим доступа: http://www.elitarium.ru/ nejming_pravilno_nazvat_tovar_biznes/(дата обращения: 31.10.2016). - Загл с экрана.

Стернин, И. А. Фактор адресата в речевом воздействии / И. А. Стернин // Вестник Воронежского государственного университета. Серия «Филология. Журналистика». - 2004. - № 1. - С. 171-178.

Стиль рекламы: речевые формы / И. П. Лапинская, М. А. Денисова, О. В. Гостева [и др.] ; под ред. И. П. Лапинской. - Воронеж : Воронежский государственный технический университет, 2016. - 161 с.

Что в имени? / И. П. Лапинская, М. А. Денисова, Д. А. Сорокина [и др.] ; под ред. И. П. Лапинской. - Воронеж : Воронежский государственный технический университет, 2016. - 219 с.

\section{СЛОВАРИ}

Ожегов - Ожегов, С. И. Толковый словарь русского языка / С. И. Ожегов, Н. Ю. Шведова. -2-е изд., испр. и доп. - М. : АЗЬ, 1994. - 928 с.

Проверка слова - Проверка слова // Грамота.py. - Электрон. дан. - Режим доступа: http:// www.gramota.ru/slovari/dic/ (дата обращения: 23.06.2017). - Загл. с экрана.

\section{REFERENCES}

Gosteva O.V. Semanticheskaya model kommercheskoy nominatsii (na materiale nazvaniy tsvetochnykh magazinov g. Voronezha i g. Birmingema) [Semantic Model of Commercial Naming (a Case Study of Names ofFlorist Shops in Voronezh and in Birmingham)]. Aktualnye problemy $i$ sovremennye tekhnologii prepodavaniya inostrannykh yazykov $v$ nespetsialnykh vuzakh: materialy 6-y Vseros. s mezhdunar. uchastiem nauchn.-prakt. konf. neyazykovykh vuzov na baze VGIFK [Current Issues and Modern Technologies of Foreign Language Teaching in Non-Linguistic Universities. Proceedings of the $6^{\text {th }}$ all-Russian with International Participation Research-to-Practice Conference of NonLinguistic Universities at VSPEI]. Voronezh, Nauchnaya kniga Publ., 2013, pp. 97-99.

Lapinskaya I.P.Antroponimykak nazvaniya biznesobyektov [Anthroponyms as Names of BusinessObjects]. Russkaya rech, 2016, no. 1, pp. 76-81.

Lapinskaya I.P., Gosteva O.V. Sistemnost imen sobstvennykh biznes-obyektov v yazyke reklamy [Systematicity of Proper Names of Business-Objects in the Advertising Language]. Vestnik Voronezhskogo gosudarstvennogo universiteta. Seriya «Lingvistika $i$ mezhkulturnaya kommunikatsiya», 2015, no. 4, pp. 42-47.

Pimenov P.A. Neyming: kak pravilno nazvat tovar ili biznes [Naming: How to Name a Commodity or a Business Correctly]. URL: http://www.elitarium.ru/ nejming_pravilno_nazvat_tovar_biznes/. (accessed October 31, 2016).

Sternin I.A. Faktor adresata v rechevom vozdeystvii [Addressee Factor in Linguistic Manipulation]. Vestnik Voronezhskogo gosudarstvennogo universiteta. Seriya "Filologiya. Zhurnalistika», 2004, no. 1, pp. 171-178.

Lapinskaya I.P., Denisova M.A., Gosteva O.V. Stil reklamy: rechevye formy [The Style of Advertising]. Voronezh, Voronezhskiy gosudarstvennyy tekhnicheskiy universitet Publ., 2016. 161 p.

Lapinskaya I.P., ed. Chto v imeni? [What Is in a Name?]. Voronezh, Voronezhskiy gosudarstvennyy tekhnicheskiy universitet Publ., 2016. 219 p.

\section{DICTIONARIES}

Ozhegov S.I., Shvedova N.Yu. Tolkovyy slovar russkogo yazyka [Explanatory Dictionary of the Russian Language]. Moscow, AZЪ Publ., 1994. 928 p. Proverka slova [Checking Word]. Gramota.ru. URL: http://www.gramota.ru/slovari/dic/. (accessed June 23, 2017). 


\section{МАТЕРИАЛЫ И СООБЩЕНИЯ}

\section{Information About the Author}

Olga V. Gosteva, Teacher, Department of Foreign Languages and Technology of Translation, Voronezh State Technical University, Prosp. Moskovskiy, 14, 394026 Voronezh, Russian Federation, ovgost@mail.ru, http://orcid.org/0000-0002-0970-0914.

\section{Информация об авторе}

Ольга Владимировна Гостева, преподаватель кафедры иностранных языков и технологии перевода, Воронежский государственный технический университет, просп. Московский, 14, 394026 г. Воронеж, Российская Федерация, ovgost@mail.ru, http://orcid.org/0000-0002-0970-0914. 